\title{
Sufentanil Disposition and Pharmacokinetic Model-Based Dosage Regimen for Sufentanil in Ventilated Full-Term Neonates
}

\author{
Pavla Pokornáa, b, c Martin Šíma ${ }^{a}$ Birgit Koch $^{d}$ Dick Tibboel b, c Ondřej Slanařa \\ aDepartment of Pharmacology, First Faculty of Medicine, Charles University and General University Hospital in Prague, \\ Prague, Czech Republic; ${ }^{b}$ Department of Paediatrics and Inherited Metabolic Disorders, First Faculty of Medicine, \\ Charles University and General University Hospital in Prague, Prague, Czech Republic; 'Intensive Care and Department \\ of Paediatric Surgery, Erasmus MC, Sophia Children's Hospital, University Medical Center, Rotterdam, The Netherlands; \\ ${ }^{\mathrm{d}}$ Department of Hospital Pharmacy, Erasmus MC, University Medical Center, Rotterdam, The Netherlands
}

\section{Keywords}

Neonate $\cdot$ Sufentanil $\cdot$ Pharmacokinetics · Dosage regimen · Critical care

\begin{abstract}
Introduction: Sufentanil is a potent synthetic opioid used for analgesia in neonates; however, data concerning drug disposition of sufentanil and dosage regimen are sparse in this population. Therefore, the aim of the study was to explore sufentanil disposition and to propose optimal loading and maintenance doses of sufentanil in ventilated full-term neonates. Methods: Individual sufentanil pharmacokinetic parameters were calculated based on therapeutic drug monitoring data using a 2-compartmental model. Linear regression models were used to explore the covariates. Results: The median (IQR) central volume of distribution $\left(\mathrm{Vd}_{\mathrm{c}}\right)$ and clearance $(\mathrm{CL})$ for sufentanil were $4.7(4.1-5.4) \mathrm{L} / \mathrm{kg}$ and 0.651 (0.433-0.751) L/h/kg, respectively. Linear regression models showed relationship between $\mathrm{Vd}_{\mathrm{c}}(\mathrm{L})$ and $\mathrm{GA}\left(r^{2}=0.3436\right.$; $p=0.0452)$ as well as BW $\left(r^{2}=0.4019 ; p=0.0268\right)$. Median optimal sufentanil LD and MD were 2.13 (95\% Cl: 1.78-2.48) $\mu \mathrm{g} / \mathrm{kg}$ and 0.29 (95\% Cl: $0.22-0.37) \mu \mathrm{g} / \mathrm{kg} / \mathrm{h}$, respectively. Median daily COMFORT-B (IQR) scores ranged from 6 to 23
\end{abstract}

karger@karger.com www.karger.com/pha

Karger $\stackrel{\text { ' }}{5}$

BOPEN ACCESS
(C) 2021 The Author(s)

Published by S. Karger AG, Basel

This is an Open Access article licensed under the Creative Commons Attribution-NonCommercial-4.0 International License (CC BY-NC) (http://www.karger.com/Services/OpenAccessLicense), applicable to the online version of the article only. Usage and distribution for commercial purposes requires written permission. while no significant relationship between pharmacokinetic parameters and COMFORT-B scores was found. Discussion/ Conclusion: Body weight and gestational age were found as weak covariates for sufentanil distribution, and the dosage regimen was developed for a prospective trial.

(c) 2021 The Author(s)

Published by S. Karger AG, Basel

\section{Introduction}

Sufentanil is a potent synthetic opioid used for the analgesia approach in neonates and critically ill paediatric patients; however, data concerning drug disposition of sufentanil and dosage regimen are sparse in this population [1-5]. Sufentanil is metabolized via hepatic cytochrome P450 CYP3A4 by oxidative N-dealkylation into inactive metabolites and to a small extent excreted unchanged via the kidney (2\%). However, the maturation of CYP3A4 is not fully understood while the CYP3A4-dependent drug clearance normalized per kg of body weight is significantly reduced in neonates, and it may increase over the first month or later during the postnatal life [6, 7]. CYP3A4 appears to be expressed in the foetal liver [8]. Pharmacokinetic $(\mathrm{PK})$ data on sufentanil published in 
critically ill neonates historically described volume of distribution (Vd) of $4.15(1.01) \mathrm{L} / \mathrm{kg}$, clearance (CL) 6.7 (6.1) $\mathrm{mL} / \mathrm{min} / \mathrm{kg}$, and half-time of elimination $\left(\mathrm{t}_{1 / 2}\right) 737$ (346) $\min [4]$. A population PK model of sufentanil showed Vd of $6.87 \mathrm{~L} / \mathrm{kg}$ and CL of $10.8 \mathrm{~mL} / \mathrm{min} / \mathrm{kg}$ in critically ill paediatric patients [9]. Furthermore, recently published data concluded that maturation, inflammation, and organ failure may have impact on the cytochrome $\mathrm{P} 450$ (CYP3A4)-mediated clearance of midazolam [10, 11]. There are very limited experimental and clinical PK data of sufentanil in critically ill neonates and young infants available in the literature $[12,13]$. Therefore, we aimed to explore individual sufentanil $\mathrm{PK}$ parameters and its main covariates in order to propose, based on regression models, the optimal loading dose (LD) and maintenance dose (MD) of sufentanil in ventilated full-term neonates.

\section{Materials and Methods}

\section{Study Population}

An open-label retrospective observational study was performed in ventilated full-term neonates treated with sufentanil admitted to the Neonatal and Pediatric Intensive Care Unit of the Department of Pediatrics General University Hospital, First Faculty of Medicine Charles University in Prague from January 2014 to December 2015. At admission to the hospital, the patients' parents signed an approved general informed consent wherein they state, inter alia, that anonymous data can be used for research. The study-specific approval was issued by the local ethics committee under the No. 2219/20 S-IV. Our study follows the principles of the Declaration of Helsinki. Exclusion criteria were refusal of general informed consent.

\section{Data Retrieval}

Clinical records of all evaluated patients were reviewed to collect information concerning gender, gestational age (GA), postnatal age (PNA), body weight (BW), height, laboratory values, and medication.

\section{Treatment with Sufentanil}

Sufentanil (Sufentanil Torrex $5 \mu \mathrm{g} / \mathrm{mL}$ inj sol $5 \times 2 \mathrm{~mL}$ ) was adjusted in accordance with the summary of product characteristics. Initial bolus of $0.1-0.5 \mu \mathrm{g} / \mathrm{kg}$ i.v. was administered for $5-10 \mathrm{~min}$, followed by a continuous infusion of $0.1-0.2(0.5) \mu \mathrm{g} / \mathrm{kg} / \mathrm{h}$ i.v. and titrated to appropriate level/effects. Other analgosedative drugs were administered based on international dosing recommendation protocols. Phenobarbital was administered as $15-20 \mathrm{mg} / \mathrm{kg}$ i.v. bolus over $5 \mathrm{~min}$ followed by $3-5 \mathrm{mg} / \mathrm{kg} /$ day dose split into 2 parts every $12 \mathrm{~h}$. Midazolam was administered as $0.05-0.1 \mathrm{mg} / \mathrm{kg}$ i.v. bolus over $5 \mathrm{~min}$ followed by continuous infusion of $0.06-0.4 \mathrm{mg} /$ $\mathrm{kg} / \mathrm{h}$ to achieve desired effects in ventilated full-term neonates [14].

\section{Analgosedation Efficacy and Safety}

Drug dosing titration for pain management based on international recommendations and the protocolized analgosedation has been introduced [15]. The analgesia/sedation was assessed every $3 \mathrm{~h}$ (or more often if needed) to individualize drug dosing. Pain and sedation assessments using a COMFORT-B score were done by trained nurses. Neonate with scores $>22$ or $<11$ was considered undersedated or oversedated, respectively [16-19].

\section{PK Modelling}

Sufentanil plasma concentrations (blood samples of 50-100 $\mu \mathrm{L}$ ) were obtained as sparse sampling collections while time of samplings was precisely documented. Plasma concentrations of sufentanil were determined using a validated UPLC-MS/MS assay [20]. Individual sufentanil PK parameters - central compartment volume of distribution $\left(\mathrm{Vd}_{\mathrm{c}}\right)$, total volume of distribution $(\mathrm{Vd})$, $C L$, and distribution $\left(t_{1 / 2} \alpha\right)$ and elimination half-life $\left(t_{1 / 2} \beta\right)$ - were calculated in a 2-compartmental PK model with first-order elimination kinetics based on individual demographic and clinical data and observed sufentanil plasma levels using MWPharm $^{++}$ software (MediWare, Prague, Czech Republic). The sufentanil PK data derived from Greeley et al. [4] (mean \pm SD Vd $c$, CL, $t_{1 / 2} \alpha$, and $\mathrm{t}_{1 / 2} \beta$ of $4.15 \pm 1.01 \mathrm{~L} / \mathrm{kg}, 0.402 \pm 0.366 \mathrm{~L} / \mathrm{h} / \mathrm{kg}, 0.39 \pm 0.29 \mathrm{~h}$, and $12.28 \pm 5.77 \mathrm{~h}$, respectively) were used for a priori simulation of the concentration-time profile in each patient. These simulated PK profile curves were a posteriori individualized to maximize fitting with observed concentration points. The fitting was performed using the Bayesian method. The goodness of fit was expressed using weighted sum of squares and root mean square values.

\section{Data Analysis and Statistics}

Optimal LD were calculated for each patient based on individual values of $\mathrm{Vd}_{\mathrm{c}}$ using the following formula: $\mathrm{LD}(\mu \mathrm{g} / \mathrm{kg})=\mathrm{Vd}(\mathrm{L} /$ $\mathrm{kg}) \times \mathrm{C}_{\mathrm{ss}}(\mu \mathrm{g} / \mathrm{L})$, where $\mathrm{C}_{\mathrm{ss}}$ is $0.45 \mu \mathrm{g} / \mathrm{L}$ as a midpoint of the sufentanil target steady-state therapeutic range $(0.3-0.6 \mu \mathrm{g} / \mathrm{L})$. Optimal daily MD were calculated for each patient based on individual values of CL using the following formula: MD $(\mu \mathrm{g} / \mathrm{kg} / \mathrm{h})=\mathrm{CL}(\mathrm{L} /$ $\mathrm{kg} / \mathrm{h}) \times \mathrm{C}_{\mathrm{ss}}(\mu \mathrm{g} / \mathrm{L})$, where $\mathrm{C}_{\mathrm{ss}}$ is $0.45 \mu \mathrm{g} / \mathrm{L}$ as a midpoint of the sufentanil target steady-state therapeutic range $(0.3-0.6 \mu \mathrm{g} / \mathrm{L})[21]$.

Descriptive parameters, median and interquartile range (IQR), were calculated using MS Excel 2010 (Microsoft Corporation, Redmond, WA, USA). The $95 \%$ confidence intervals (CI) for medians were calculated by the Bonett and Price [22] method. Linear regression models were used to evaluate the relationships of sufentanil $\mathrm{PK}$ parameters $\left(\mathrm{Vd}_{\mathrm{c}}, \mathrm{Vd}_{\text {tot }}\right.$, and $\left.\mathrm{CL}\right)$ and patients' demographic characteristics (BW, GA, and PNA) using GraphPad Prism 8.2.1 software (GraphPad Inc., La Jolla, CA, USA). The same method was used to assess relationships between $\mathrm{PK}$ parameters or median levels of sufentanil and median COMFORT-B scores or proportions of COMFORT-B scores in the target range. $p$ levels $<0.05$ were considered statistically significant.

\section{Results}

\section{Study Population}

Twelve ( 9 female and 3 male) neonates with median (IQR) BW of $3.18(2.89-3.86) \mathrm{kg}$, GA of 39 (37-40) weeks, and PNA at the start of treatment of $9(2-30)$ hours were included in the analysis. Demographic and clinical details 
Table 1. Demographics and clinical characteristics of the population

\begin{tabular}{lc}
\hline Demography & \\
Age, h, at the start of treatment & $39(2-30)$ \\
GA, weeks & $3.17(2.88-3.80)$ \\
Birth BW, kg & $9 / 3(75 / 25)$ \\
Sex, female/male, $n(\%)$ & $10(83)$ \\
Survival, $n(\%)$ & \\
Laboratory values at the start of treatment & $70.0(66.0-77.0)$ \\
Creatinine, $\mu$ mol/L & $4.45(3.05-5.9)$ \\
Urea, mmol/L & $40.9(32.9-73.6)$ \\
Total bilirubin, $\mu$ mol/L & $6.75(6.02-8.52)$ \\
Direct bilirubin, $\mu$ mol/L & $26.7(25.9-28.8)$ \\
Albumin, g/L & $1.0(1.0-1.1)$ \\
C-reactive protein, mg/L & $78.0(12.9-110.4)$ \\
Aspartate transaminase, IU/L & $28.8(14.4-44.1)$ \\
Alanine transaminase, IU/L & \\
Concomitant treatments & $12(100)$ \\
Ventilatory support, $n(\%)$ & $11(92)$ \\
Circulatory support, $n(\%)$ & $8(67)$ \\
Inotropics/vasopressors, $n(\%)$ & $10(83)$ \\
Midazolam, $n$ (\%) & $12(100)^{\dagger}$ \\
Other analgesic/sedative drugs, $n(\%)$ &
\end{tabular}

Data are presented as median (IQR). GA, gestational age; BW, body weight. ${ }^{\dagger}$ From those, 12 neonates received phenobarbital, 2 phenytoin, and 1 clonidine and tramadol.

are presented in Table 1. Sufentanil dose ranged between 0.005 and $0.72 \mu \mathrm{g} / \mathrm{kg} / \mathrm{h}$. Duration of sufentanil treatment was 2-11 days.

\section{Analgosedation Efficacy and Safety}

In total, 509 COMFORT-B scores were obtained (1657 per patient). There were $38.5 \%$ of COMFORT-B scores in the target range (11-22), while 61.3 and $0.2 \%$ were $<11$ and $>22$, respectively. No severe bradycardia and systemic hypotension were documented concerning the treatment with sufentanil.

\section{Sufentanil Pharmacokinetics}

In total, 232 sufentanil plasma levels were obtained with a median (range) number of samples of 19 (8-27) per patient. The distribution of sufentanil concentration points over the time is presented in Figure 1. PK analysis is summarized in Table 2. Median (IQR) weighted sum of squares and root mean square values were 12.61 (7.67$18.79)$ and 1.03 (1.01-1.07), respectively. We observed medium to high inter-individual variability of PK parameters normalized per kg of body weight demonstrated by a coefficient of variation of 25,38 , and $59 \%$ for $\mathrm{Vd}_{c}, \mathrm{Vd}_{\text {tot }}$, and CL, respectively.

\section{Regression Models and Dosing Proposal}

Linear regression models showed significant dependence of $\mathrm{Vd}_{\mathrm{c}}(\mathrm{L})$ on $\mathrm{GA}\left(r^{2}=0.3436 ; p=0.0452\right)$ and BW $\left(r^{2}=0.4019 ; p=0.0268\right)$. The other tested relationships were without statistical significance. Relationships between PK parameters and BW (for the purpose of dosing proposal) are demonstrated in Figure 2.

Median optimal sufentanil LD and MD calculated based on observed PK data were 2.13 (95\% CI: 1.78-2.48) $\mu \mathrm{g} / \mathrm{kg}$ and 0.29 (95\% CI: $0.22-0.37) \mu \mathrm{g} / \mathrm{kg} / \mathrm{h}$, respectively. When we simulated administration of this $\mathrm{LD}$ on the model with each individual's PK data, 11 patients (92\%) reached the target range for sufentanil concentrations $(0.3-0.6 \mu \mathrm{g} / \mathrm{L})$, while 1 patient $(8 \%)$ was above the range. Simulation of the above-mentioned MD led to 6 patients $(50 \%)$ in the target range, while 5 patients $(42 \%)$ were above and 1 patient $(8 \%)$ was under the range. There were no relationships between $\mathrm{PK}$ parameters or median levels of sufentanil and median COMFORT-B scores or proportions of COMFORT-B scores in the target range.

\section{Discussion}

Our work explored sufentanil disposition and dosage regimen for sufentanil in ventilated full-term neonates treated with sufentanil for prolonged analgesia. Overall, we have found PK parameters ( $\mathrm{Vd}, \mathrm{CL}$, and $\mathrm{t}_{1 / 2}$ ) similar to data published in neonates [4]. The highest inter-subject PK variability was shown for CL (59\%) likely reflecting the ontogenetic maturation of elimination of sufentanil.

We reported similar PK parameters to data and trend published for paediatric population in intensive care units compared to normal children $[3-5,23]$. Vd was reported large and CL decreased, and therefore $t_{1 / 2}$ prolonged, in neonates in comparison with young infants and older children $[4,7]$. No data have been reported in preterm neonates except sufentanil dosage reduction in extremely low-birth-weight neonates after patent ductus arteriosus surgery [24]. For preterm neonates and neonates, low CL is expected as well as low protein binding (free fraction of sufentanil about 19.5\%) and large variation in drug disposition compared to young infants and older children $[4,25]$.

Median optimal sufentanil LD and MD were calculated based on observed PK data. To calculate the optimal doses, we used the range of $0.3-0.6 \mu \mathrm{g} / \mathrm{L}$ as the PK target for efficacious and safe analgesia [21], while higher levels have been described for anaesthetic effects in the litera- 


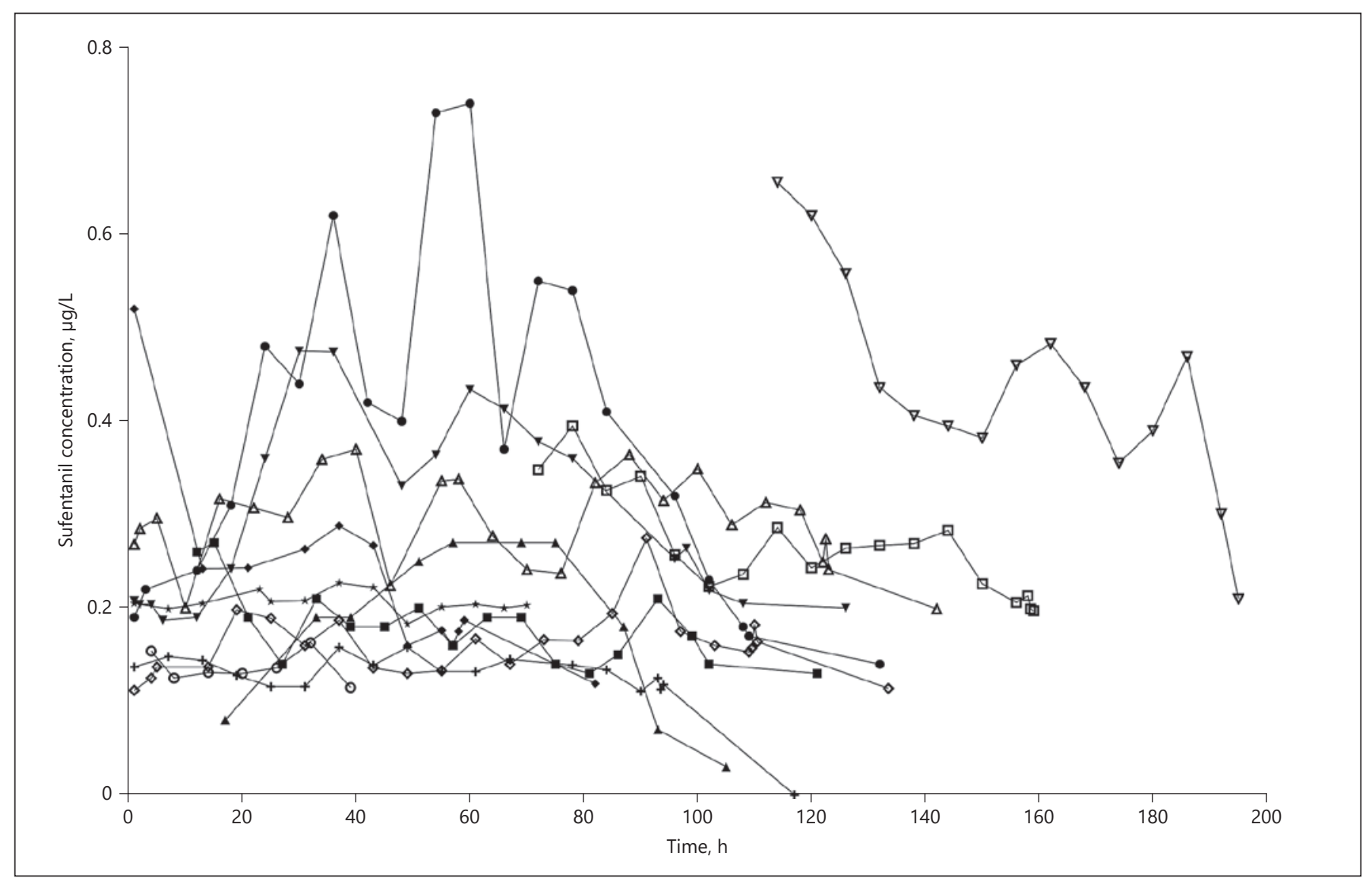

Fig. 1. Individual sufentanil concentration points over the time in 12 neonates.

Table 2. PK analysis of sufentanil in neonates

\begin{tabular}{lrcc}
\hline & Median & \multicolumn{1}{l}{ IQR } & \multicolumn{1}{l}{ Range } \\
\hline $\mathrm{Vd}_{\mathrm{c}}, \mathrm{L}$ & 15.5 & $13.2-17.9$ & $6.3-25.4$ \\
$\mathrm{Vd}_{\mathrm{c}}, \mathrm{L} / \mathrm{kg}$ & 4.7 & $4.1-5.4$ & $2.3-6.6$ \\
$\mathrm{Vd}_{\text {tot }}, \mathrm{L}$ & 39.5 & $24.4-49.7$ & $17.4-71.0$ \\
$\mathrm{Vd}_{\text {tot }}, \mathrm{L} / \mathrm{kg}$ & 11.8 & $7.7-15.4$ & $6.3-18.2$ \\
$\mathrm{CL}, \mathrm{L} / \mathrm{h}$ & 1.9 & $1.5-2.9$ & $1.1-5.4$ \\
$\mathrm{CL}, \mathrm{L} / \mathrm{h} / \mathrm{kg}$ & 0.651 & $0.433-0.751$ & $0.358-1.872$ \\
$\mathrm{t}_{1 / 2 \alpha}, \mathrm{h}$ & 0.0263 & $0.0260-0.0264$ & $0.0230-0.0264$ \\
$\mathrm{t}_{1 / 2 \beta}, \mathrm{h}$ & 13.3 & $9.4-16.7$ & $5.18-21.3$ \\
\hline
\end{tabular}

PK, pharmacokinetic.

ture [26]. Currently, the usual induction and maintenance doses of sufentanil are $0.25-2.0$ and $0.5-1.5 \mu \mathrm{g} /$ $\mathrm{kg} / \mathrm{h}$, respectively [11, 27-29]. Our results indicate that the respective doses of $2.13 \mu \mathrm{g} / \mathrm{kg}$ and $0.29 \mu \mathrm{g} / \mathrm{kg} / \mathrm{h}$ could be used. While the proposed LD is on the upper limit of the currently used dosing range, the MD is lower than

Sufentanil Pharmacokinetics and Dosing in Neonates that currently considered, which corresponds to the relatively low CL of the drug in our study group, which was however similar to the previously published data. The doses are normalized to BW as a marker for maturation in this patient population [30,31]. However, nonmaturational covariates inflammation and organ failure may also play important role in sufentanil drug disposition in neonates. Additionally, treatment modality (ECMO) superimposed on disease may lead to changes in sufentanil PK parameters [32]. Individual PK-based studies are generally conducted in order to describe PK parameters and determine the most prominent factors with highest potential to affect drug exposures. Although this individual approach leaves many possible sources of variability unexplored, the most important ones are generally better captured in limited sample size population provided that sufficient number of samples can be obtained. Our study population included frequent TDM data from 12 subjects. Due to the sample-rich database and relatively low span of the investigated covariates, we chose the individ- 


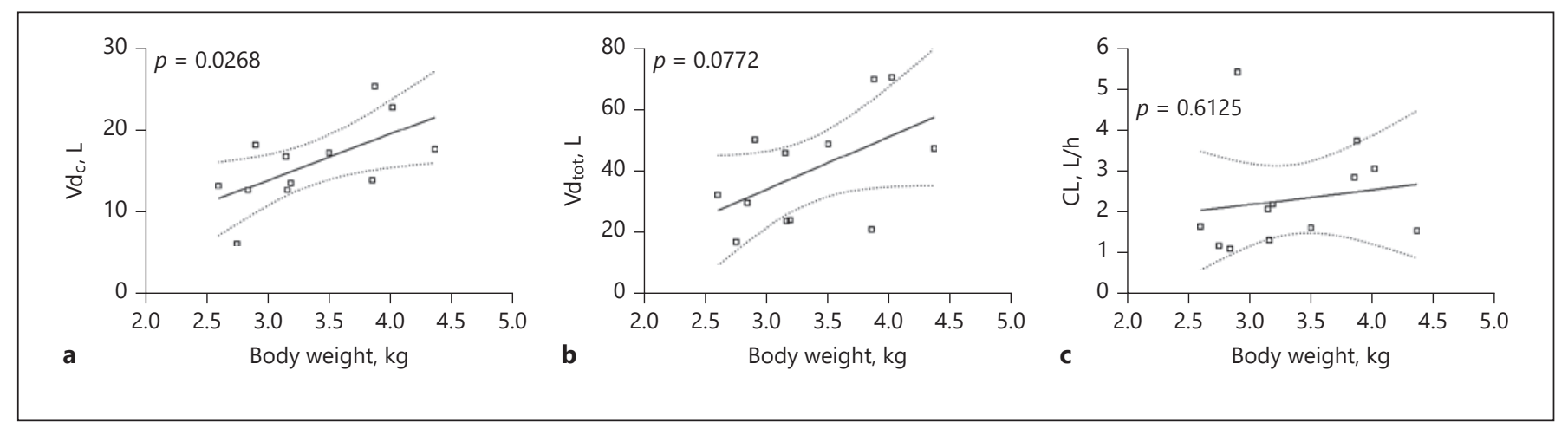

Fig. 2. Relationship between sufentanil pharmacokinetic parameters (central volume of distribution (a), total volume of distribution (b), and clearance (c)) and body weight (for the purpose of dosing proposal).

ual-based approach. An advantage of our study is that it directly uses metrics and procedures that are a gold standard in routine clinical care and dose adjustments.

Limitation of this study is a small size of the investigated group since it deals with a very specific cohort. Our study has also not addressed PK/PD relationship. Although no relationship between sufentanil serum levels and COMFORT-B score has been noted, this is likely affected by comedication. No detailed PK/PD examinations have been conducted due to limited number of subjects. Furthermore, the proposal for LD and MD results from a PK analysis only and should thus be used for a prospective clinical trial to verify its efficacy and safety in routine clinical use.

In conclusion, BW and GA were found as covariates of sufentanil distribution. Sufentanil LD of $2.13 \mu \mathrm{g} / \mathrm{kg}$ and $\mathrm{MD}$ of $0.29 \mu \mathrm{g} / \mathrm{kg} / \mathrm{h}$ should be verified in clinical trials for the use in ventilated full-term neonates treated for prolonged analgesia.

\section{Statement of Ethics}

The study was approved by the local ethics committee under the No. 2219/20 S-IV. At admission to the hospital, the patients' parents signed an approved general informed consent wherein they state, inter alia, that anonymous data can be used for research. Exclusion criteria were refusal of general informed consent. Our study follows the principles of the Declaration of Helsinki.

\section{Conflict of Interest Statement}

The authors have no conflicts of interest to declare.

\section{Funding Sources}

This work was supported by the Ministry of Health of the Czech Republic project MH CZ-DRO-VFN64165, by the Charles University project PROGRES Q25/LF1 and SVV 260523, by an unrestricted research grant of the Intensive Care Unit of the Erasmus MCSophia Children's Hospital, and by the project UNCE204064 (the Innovative Medicines Initiative 2, Grant Agreement No. 777389 from the European Union's Horizon 2020 and EFPIA).

\section{Author Contributions}

P.P. and M.S. designed the study, P.P. gave the clinical support, B.K. performed laboratory diagnostics, P.P. and B.K. collected data, M.S. analysed data, P.P. and M.S. wrote the manuscript (original draft preparation), D.T. and O.S. wrote the manuscript (review and editing), and D.T. and O.S. gave conceptual advice. All coauthors have agreed to the submission of the final manuscript.

\section{References}

1 Baarslag MA, Allegaert K, Knibbe CA, van Dijk M, Tibboel D. Pharmacological sedation management in the paediatric intensive care unit. J Pharm Pharmacol. 2017;69(5):498-513.

2 Lundeberg S, Roelofse JA. Aspects of pharmacokinetics and pharmacodynamics of sufentanil in pediatric practice. Paediatr Anaesth. 2011;21(3):274-9.
3 Davis PJ, Cook DR, Stiller RL, Davin-Robinson KA. Pharmacodynamics and pharmacokinetics of high-dose sufentanil in infants and children undergoing cardiac surgery. Anesth Analg. 1987;66(3):203-8.

4 Greeley WJ, de Bruijn NP, Davis DP. Sufentanil pharmacokinetics in pediatric cardiovascular patients. Anesth Analg. 1987;66(11):1067-72.
5 Davis PJ, Stiller RL, Cook DR, Brandom BW, Davin-Robinson KA. Pharmacokinetics of sufentanil in adolescent patients with chronic renal failure. Anesth Analg. 1988;67(3):26871.

6 Anderson BJ, Meakin GH. Scaling for size: some implications for paediatric anaesthesia dosing. Paediatr Anaesth. 2002;12(3):205-19. 
7 Greeley WJ, de Bruijn NP. Changes in sufentanil pharmacokinetics within the neonatal period. Anesth Analg. 1988;67(1):86-90.

8 Lacroix D, Sonnier M, Moncion A, Cheron G, Cresteil T. Expression of CYP3A in the human liver--evidence that the shift between CYP3A7 and CYP3A4 occurs immediately after birth. Eur J Biochem. 1997;247(2):625-34.

9 Bartkowska-Sniatkowska A, Bienert A, Wiczling P, Rosada-Kurasinska J, Zielinska M, Warzybok J, et al. Pharmacokinetics of sufentanil during long-term infusion in critically ill pediatric patients. J Clin Pharmacol. 2016; 56(1):109-15.

10 Brussee JM, Vet NJ, Krekels EHJ, Valkenburg AJ, Jacqz-Aigrain E, van Gerven JMA, et al. Predicting CYP3A-mediated midazolam metabolism in critically ill neonates, infants, children and adults with inflammation and organ failure. Br J Clin Pharmacol. 2018;84(2):35868.

11 Zhou W, Johnson TN, Bui KH, Cheung SYA, $\mathrm{Li}$ J, Xu H, et al. Predictive performance of physiologically based pharmacokinetic (PBPK) modeling of drugs extensively metabolized by major cytochrome P450s in children. Clin Pharmacol Ther. 2018;104(1):188200.

12 Schmidt B, Adelmann C, Stützer H, Welzing L, Hünseler C, Kribs A, et al. Comparison of sufentanil versus fentanyl in ventilated term neonates. Klin Padiatr. 2010;222(2):62-6.

13 Ziesenitz VC, Vaughns JD, Koch G, Mikus G, van den Anker JN. Pharmacokinetics of fentanyl and its derivatives in children: a comprehensive review. Clin Pharmacokinet. 2018;57(2):125-49.

14 Taketomo CK, Hodding JH, Kraus DM. Pediatric \& neonatal dosage handbook. 20th ed. Hudson, Ohio: Lexi-Comp; 2013.
15 Harris J, Ramelet AS, van Dijk M, Pokorna P, Wielenga J, Tume L, et al. Clinical recommendations for pain, sedation, withdrawal and delirium assessment in critically ill infants and children: an ESPNIC position statement for healthcare professionals. Intensive Care Med. 2016;42(6):972-86.

16 van Dijk M, Peters JW, van Deventer P, Tibboel D. The comfort behavior scale: a tool for assessing pain and sedation in infants. Am J Nurs. 2005;105(1):33-6.

17 Valkenburg AJ, Boerlage AA, Ista E, Duivenvoorden HJ, Tibboel D, van Dijk M. The comfort-behavior scale is useful to assess pain and distress in 0 to 3-year-old children with down syndrome. Pain. 2011;152(9):2059-64.

18 van Dijk M, de Boer JB, Koot HM, Tibboel D, Passchier J, Duivenvoorden HJ. The reliability and validity of the comfort scale as a postoperative pain instrument in 0 to 3 -year-old infants. Pain. 2000;84(2-3):367-77.

19 Ista E, van Dijk M, Tibboel D, de Hoog M. Assessment of sedation levels in pediatric intensive care patients can be improved by using the comfort "behavior" scale. Pediatr Crit Care Med. 2005;6(1):58-63.

20 Flint RB, Bahmany S, van der Nagel $\mathrm{BCH}$, Koch BCP. Simultaneous quantification of fentanyl, sufentanil, cefazolin, doxapram and keto-doxapram in plasma using liquid chromatography-tandem mass spectrometry. Biomed Chromatogr. 2018;32(10):e4290.

21 Hahn J, Yang S, Min KL, Kim D, Jin BH, Park $\mathrm{C}$, et al. Population pharmacokinetics of intravenous sufentanil in critically ill patients supported with extracorporeal membrane oxygenation therapy. Crit Care. 2019;23(1):248.

22 Bonett DG, Price RM. Statistical inference for a linear function of medians: confidence intervals, hypothesis testing, and sample size requirements. Psychol Methods. 2002;7(3): $370-83$.

23 Guay J, Gaudreault P, Tang A, Goulet B, Varin F. Pharmacokinetics of sufentanil in normal children. Can J Anaesth. 1992;39(1):1420.
24 Soreze Y, Audureau E, Decobert F, Jaby O, Blary S, Danan C, et al. Reduced sufentanil doses are effective for postoperative analgesia after ductal closure in extremely premature infants: a 10 years retrospective cohort study. Clin J Pain. 2017;33(12):1109-16.

25 Meistelman C, Benhamou D, Barre J, Levron JC, Mahe V, Mazoit X, et al. Effects of age on plasma protein binding of sufentanil. Anesthesiology. 1990;72(3):470-3.

26 Bailey JM, Schwieger IM, Hug CC Jr. Evaluation of sufentanil anesthesia obtained by a computer-controlled infusion for cardiac surgery. Anesth Analg. 1993;76(2):247-52.

27 Lotsch J. Pharmacokinetic-pharmacodynamic modeling of opioids. J Pain Symptom Manage. 2005;29(5 Suppl 1):S90-103

28 Tegenge MA, Mahmood I. Age- and bodyweight-dependent allometric exponent model for scaling clearance and maintenance dose of theophylline from neonates to adults. Ther Drug Monit. 2018;40(5):635-41.

29 Tegenge MA, Mahmood I, Jiang Z, Forshee R. Multistep unified models using prior knowledge for the prediction of drug clearance in neonates and infants. J Clin Pharmacol. 2018; 58(7):877-84.

30 Pokorna P, Sima M, Cerna O, Allegaert K, Tibboel D, Slanar O. Actual body weightbased vancomycin dosing in neonates. J Chemother. 2019;31(6):307-12.

31 Pokorna P, Sima M, Cerna O, Slanar O. Nomogram based on actual body weight for estimation of vancomycin maintenance dose in infants. Infect Dis. 2019;51(5):334-9.

32 Pokorna P, Sima M, Vobruba V, Baskova M, Posch L, Slanar O. Sufentanil pharmacokinetics in a full-term neonate treated with extracorporeal membrane oxygenation: a case report. Perfusion. 2019;34(5):433-6. 